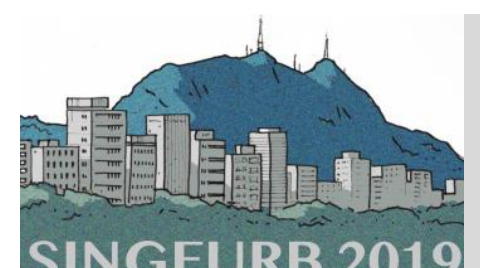

II Simpósio Nacional de Gestão e Engenharia Urbana

ABORDAGEM SISTÊMICA, ESCALAS E INTERSETORIALIDADE: DESAFIOS E POTENCIAIS DO DESENVOLVIMENTO URBANO SUSTENTÁVEL

27 a 29 de novembro - USP

\title{
Escutando comunidades atingidas pelo rompimento da barragem da Samarco no Rio Doce: resultados iniciais do Espírito Santo, Brasil 1
}

\author{
Listening to Communities hit by Samarcos's Rio Doce dam \\ collapse: initial results from Espirito Santo, Brazil
}

\author{
Leirner, André1; LaValle, Adrian G.2; Albuquerque, Maria ${ }^{3}$; Rodrigues, \\ Fernando 4
}

\begin{abstract}
1 Centro Brasileiro de Análise e Planejamento - CEBRAP, R. Morgado de Mateus, 615, Vila Mariana, São Paulo - SP, Brasil, CEP 04015-051; indx.design@gmail.com

2 Universidade de São Paulo - Faculdade de Filosofia, Letras, Ciências Humanas; Layda@usp.br

${ }^{3}$ Centro Brasileiro de Análise e Planejamento - CEBRAP; mcarmoa@gmail.com

4 Universidade de São Paulo - Faculdade de Filosofia, Letras, Ciências Humanas, fernandoperesrodrigues@gmail.com
\end{abstract}

\begin{abstract}
RESUMO
O colapso da barragem de resíduos de mineração da Samarco em 2015 teve efeitos devastadores sobre o Rio Doce afetando suas comunidades de entorno. É nesse contexto que a presente pesquisa, desenvolvida no âmbito do Projeto $n^{\circ} 88881.118026 / 2016-01$ CAPES-FAPEMIG-FAPES-CNPq-ANA, procura experimentar e transferir tecnologias sociais aos habitantes da foz do rio junto ao mar e assim favorecer políticas de recuperação daquele território. Para a realização desse trabalho empregamos uma metodologia de painel de agregação preferencial de opiniões, uma ferramenta analítica interdisciplinar cujo objetivo é fomentar a reflexão coletiva e a construção de consensos, respeitando a expressão de interesses e significados implicados nas relações entre atores locais. O presente trabalho descreve sucintamente esse processo, seu modelo de dados e oferece achados parciais, inicialmente apurados. Resultados apontam que ciclos contínuos de estímulo (votação) e resposta (resultado) em âmbito coletivo criam dinâmicas sociais sistêmico-responsivas sensíveis ao contexto ambiental. Tal efeito foi observado em âmbito multiescalar e multitemático. Espera-se, com esse trabalho, contribuir para a inclusão de dinâmicas socialmente responsivas de interação coletiva no desenho e implementação de políticas públicas e assim incrementar a acuidade da alocação de bens e serviços, contribuindo para o aperfeiçoamento de práticas socialmente sustentáveis de desenvolvimento.
\end{abstract}

Palavras-chave: participação, inteligência coletiva, desenvolvimento sócio-territorial.

\begin{abstract}
The collapse of the Samarco mining waste dam in 2015 affected communities around Rio Doce river bed. The present research, developed under the project no. 88881.118026 / 2016-

1 LEIRNER, Andre; LAVALLE, Adrian G.; ALBUQUERQUE, Maria. Escutando a voz das comunidades: resultados iniciais do Espirito Santo, Brasil. In: II SIMPÓSIO NACIONAL DE GESTÃO E ENGENHARIA URBANA: SINGEURB, 2019, São Paulo. Anais... Porto Alegre: ANTAC, 2019.
\end{abstract}


01 CAPES-FAPESIG-FAPES-CNPq-ANA, seeks to experiment and transfer social technologies to local inhabitants living by the river mouth, close to the sea, and thus favor the recovery policies of that territory. To carry out this work a preferential opinion aggregation panel was deployed, an interdisciplinary analytical tool whose objective is to foster collective reflection and consensus, respecting the expression of interests and meanings implied in the relations between local actors. This paper briefly describes this process, its data model and offers partial findings. Results indicate that continuous cycles of stimulus (voting) and response (output) in collective environments create systemic-responsive social dynamics, sensitive to the environmental context. This effect was observed in a multiscale and multi-thematic scope. With this work, we hope to contribute with the inclusion of socially responsive dynamics in the design and implementation of public policies, and to increase the accuracy of public good allocation contributing to the improvement of socially sustainable development practices and outcomes.

Keywords: participation, collective intelligence, social territorial development.

\section{INTRODUÇÃO}

O colapso da barragem de resíduos de mineração da Samarco em 2015 teve efeitos devastadores sobre o Rio Doce afetando suas comunidades de entorno. É nesse contexto que a presente pesquisa, desenvolvida no âmbito do Projeto $n^{\circ} 88881.118026 / 2016-01$ CAPES-FAPEMIG-FAPES-CNPq-ANA, procura experimentar e transferir tecnologias sociais aos habitantes da foz do rio, junto ao mar, e assim favorecer políticas de recuperação daquele território.

Este trabalho está inscrito na investigação acerca de modelos de inteligência coletiva (IWANAGA \& NAMATAME, 2012, 2017; LANDEMORE, 2012, 2017), controles democráticos não eleitorais extra institucionais (IZUNZA \& GURZA, 2018) e encaixes institucionais entre sociedade civil e Estado no âmbito de domínios de agência (LAVALLE, 2017).

Esse relato procura apresentar o modelo de dados empregado e contribuir aos campos do planejamento e gestão urbana e regional.

\section{METODOLOGIA}

Para a realização desse trabalho empregamos uma metodologia de painel de agregação preferencial de opiniões. A partir de um debate solicita-se aos participantes que subscrevam manifestações sucintas por escrito sobre os diferentes aspectos do assunto em pauta. Realiza-se uma listagem das opiniões recebidas. Essa listagem é então devolvida aos participantes e distribuída em um território, ampliando o alcance da circulação de informação e permitindo os habitantes desse território se engajarem no debate, seja submetendo novas propostas, seja votando nas propostas existentes. Para tal, usam boletos e urnas especialmente desenhadas.

É permitido a cada participante votar em até 9 propostas diferentes por dia e submeter quantas propostas novas quiser. A contagem das votações é cumulativa e por período (votos acumulados no mês, por exemplo).

Realiza-se então uma nova totalização de dados e novas listas são disseminadas, intensificando-se o processo de circulação de informação e votação. Se no primeiro momento circulou-se manifestações sobre o tema em debate, nesse segundo dissemina-se manifestações ranqueadas pelas votações realizadas revelando a soma das preferências individuais dos participantes (linha de base).

A realização de ciclos de votação e proposição sucessivos permitem, por sua vez, que participantes se posicionem criticamente frente aos resultados. Ciclo contínuo, esse processo de estímulo (votação) e resposta (resultado) cria dinâmicas sistêmico-responsivas de ação coletiva sensíveis ao contexto ambiental, manifesto no elenco de prioridades 
coletivas, objeto do processo. Tal efeito foi observado em âmbito multiescalar e multitemático nas experiências realizadas.

A maturidade deste processo é alcançada quando (i) debate e discussão atingem especificidade suficiente para endereçar uma visão de futuro e informar estratégias e táticas de implementação compartilhada, e (ii), ocorre uma identificação simbólica dos usuários com o meio/mecanismo de painel, tornando-se um processo orgânico de comunicação entre esferas de deliberação, e/ou arenas de ação coletiva, e o corpo coletivo de contribuintes (governança compartilhada).

\section{DESCRIÇÃO DE TRABALHO DE CAMPO}

Descrevemos abaixo a aplicação dessa dinâmica nos municípios de Vitória, Colatina e São Mateus no Espírito Santo, agregando 9 microrregiões municipais (Serra, Guriris, Barra Nova Sul, São Miguel-llha preta, Povoação, Degredo, Bela Vista, Regência e Colatina) - figural.

Figura 1 - Mapa das regiões de consulta Set 2018 - Jan 2019

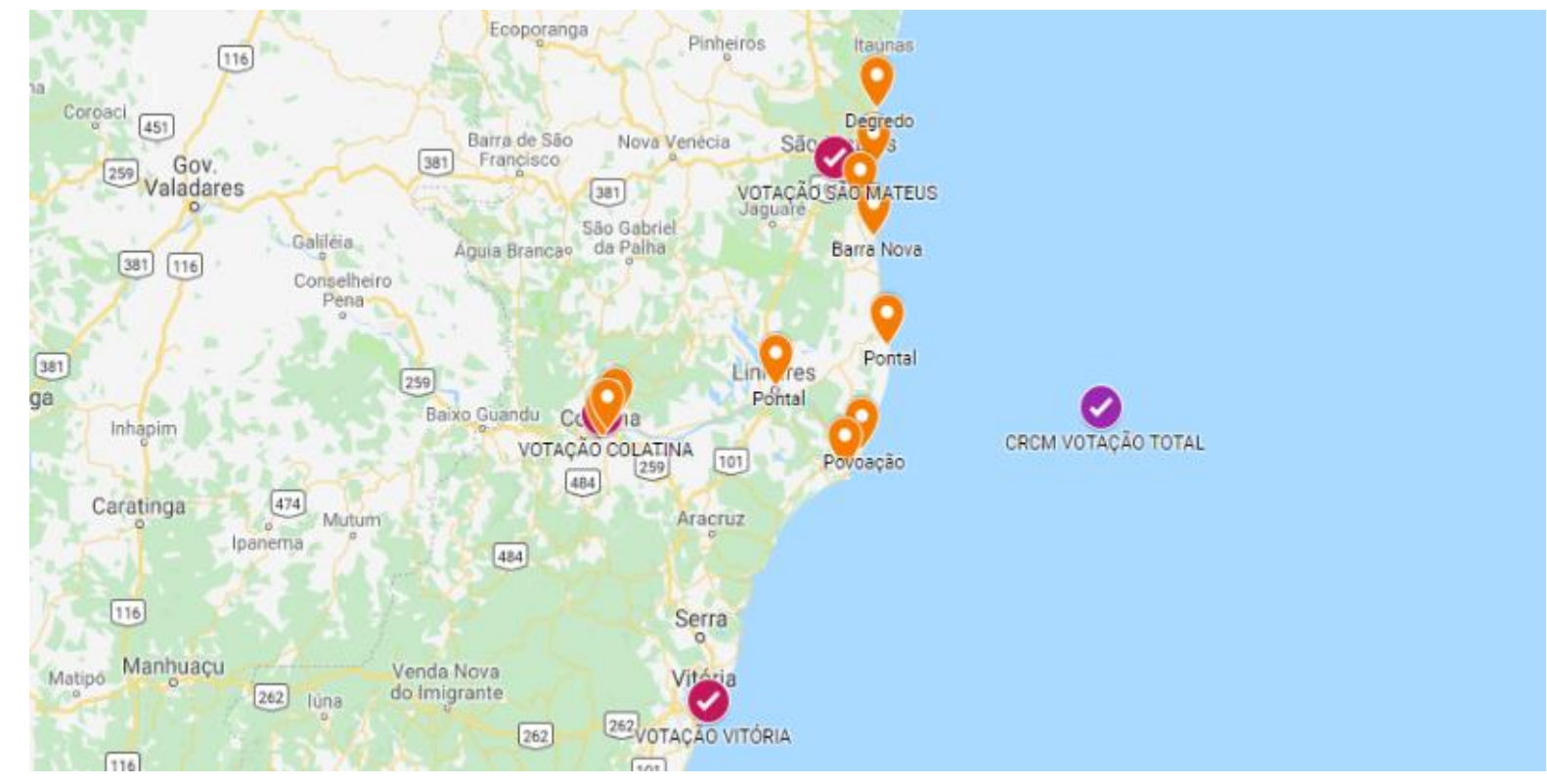

Fonte: Os autores (2019)

Nesse caso, o sistema foi aplicado em escala sub-municipal (coleta de dados), municipal (totalizações mensais, por município) e inter-municipal (totalizações trimestrais, todos municípios) - figura 2, e em âmbito multitemático (Água, Cultura/Lazer, Educação, Geral, Indenização, Justiça, Meio Ambiente, Modo de Vida, Saúde, Segurança Alimentar, Trabalho e Turismo). 
Figura 2 - Boletim regional (mensal) e Jornal (trimestral)

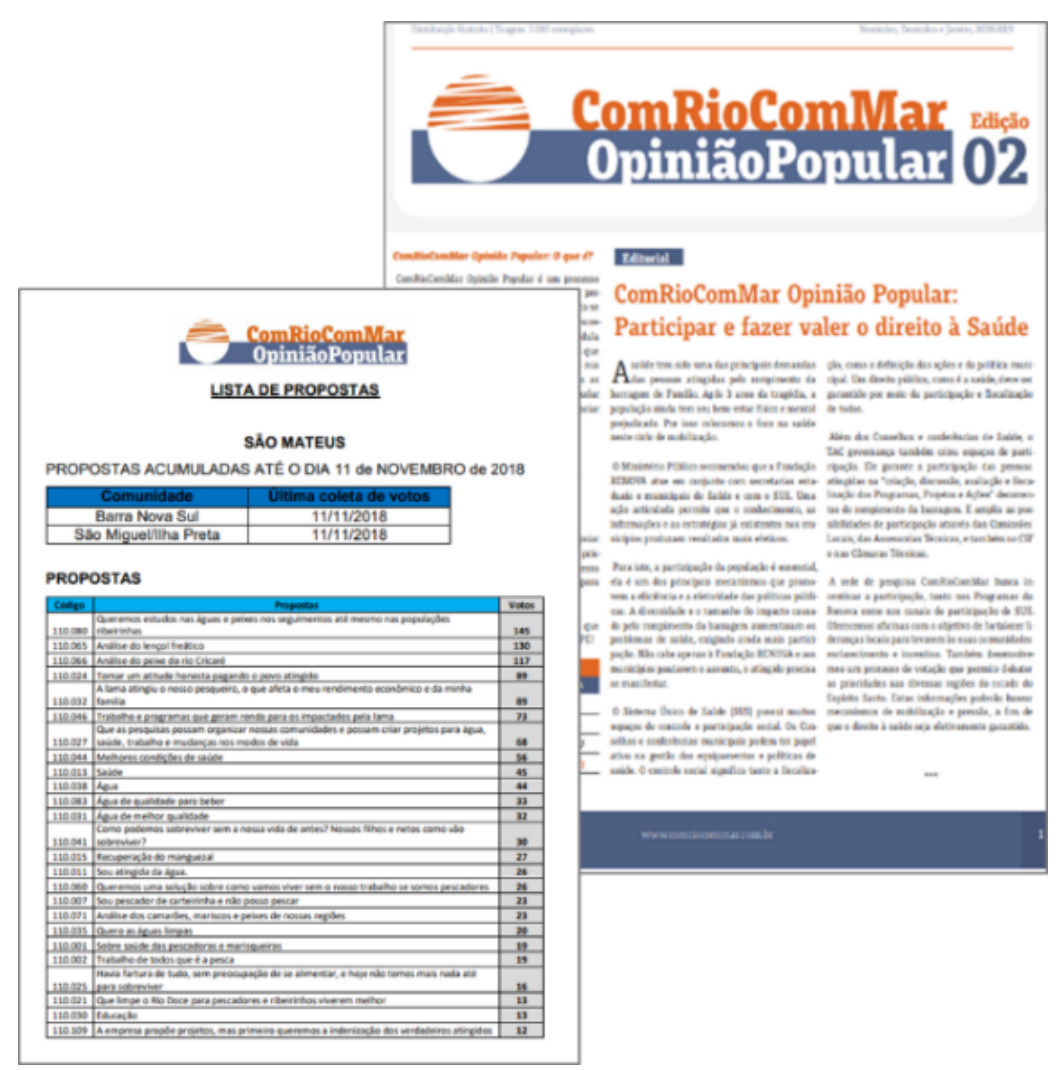

Fonte: Os autores (2019)

O debate e a coleta de proposições foram realizados pelas próprias comunidades de atingidos. Nesse processo, diferentes temas são levantados e discutidos pela população figuras 3 e 4 .

Figura 3 - Votação em São Mateus, ES

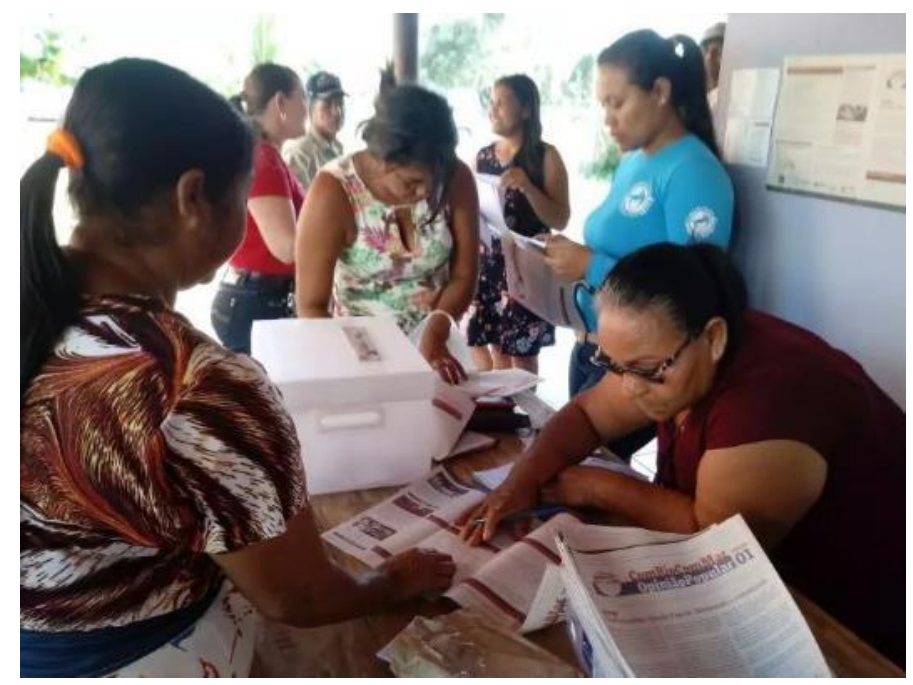

Fonte: Os autores (2019) 
Figura 4 - Cédulas de votação: face proposição e votação

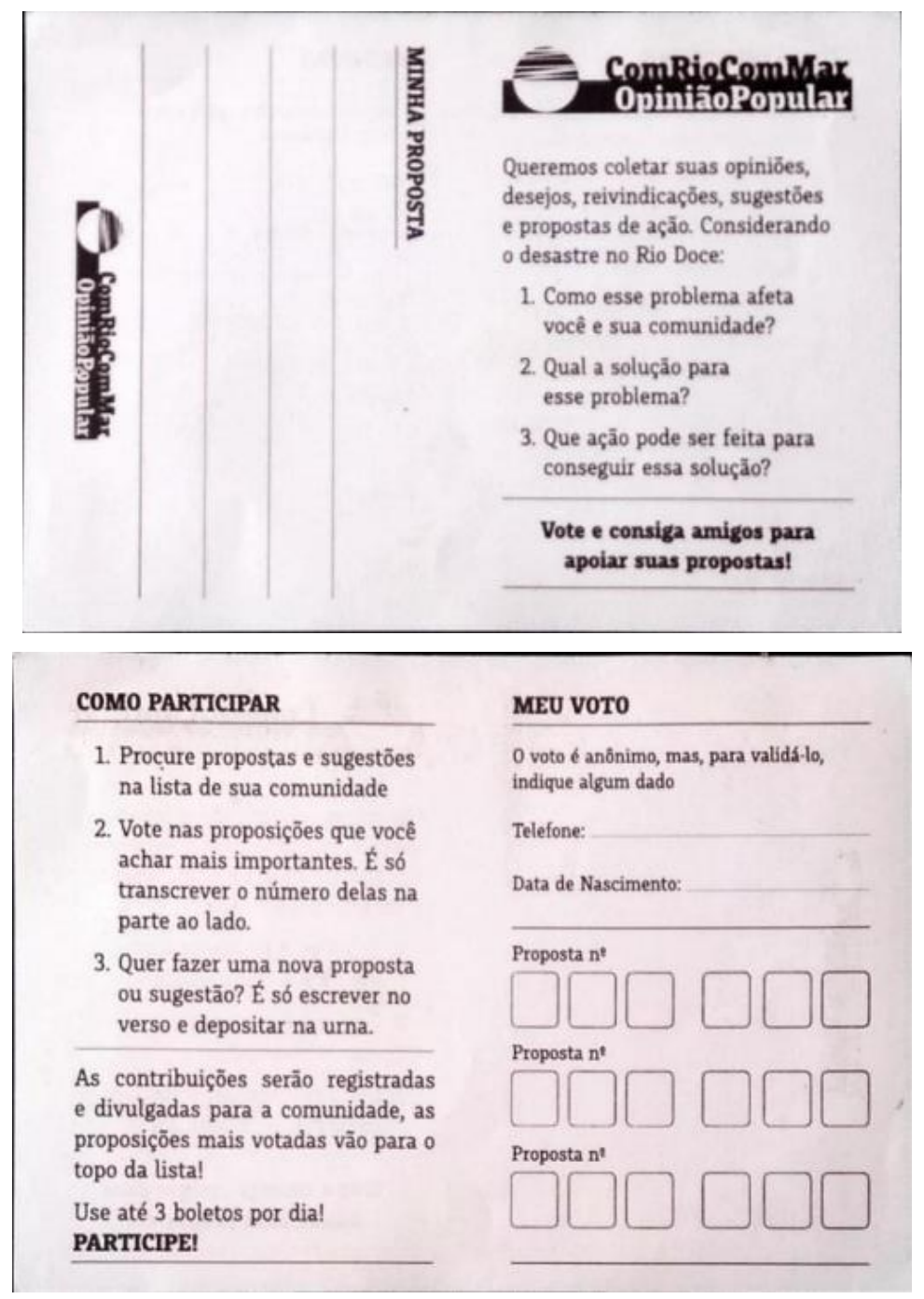

Fonte: Os autores (2019)

O grupo de pesquisa conduziu ainda oficinas trimestrais reunindo representantes de todas as regiões. A sistematização desse material foi realizada por um agente extensionista da UFES Universidade Federal do Espírito Santo, que periodicamente recolheu as contribuições recebidas em urna e as registrou por meio de formulários eletrônicos. O procedimento envolve tanto a transcrição das proposições em sistema quanto a categorização dessas proposições em temas específicos e o respectivo registro de votações de proposições por microrregião (urna). Análises de dados e totalizações foram realizadas manualmente.

\section{RESULTADOS INICIAIS}

Os resultados iniciais apresentados são resultado de 4 ciclos de coleta de dados, realizadas entre setembro de 2018 e janeiro de 2019 - considerando que de junho a setembro não houveram atividades significativas. Foram contabilizadas 861 participações de 334 participantes individuais. No processo foram contabilizadas 214 proposições priorizadas por 3341 votos acumulados. Apresentamos abaixo uma amostra dos resultados iniciais desse processo de pesquisa.

Nesse período de consulta inicial o município de São Mateus teve participação preponderante com 90\% das participações e votos realizados (Figuras 5, 6 e 7). 
Figura 5 - Espírito Santo: evolução de votações

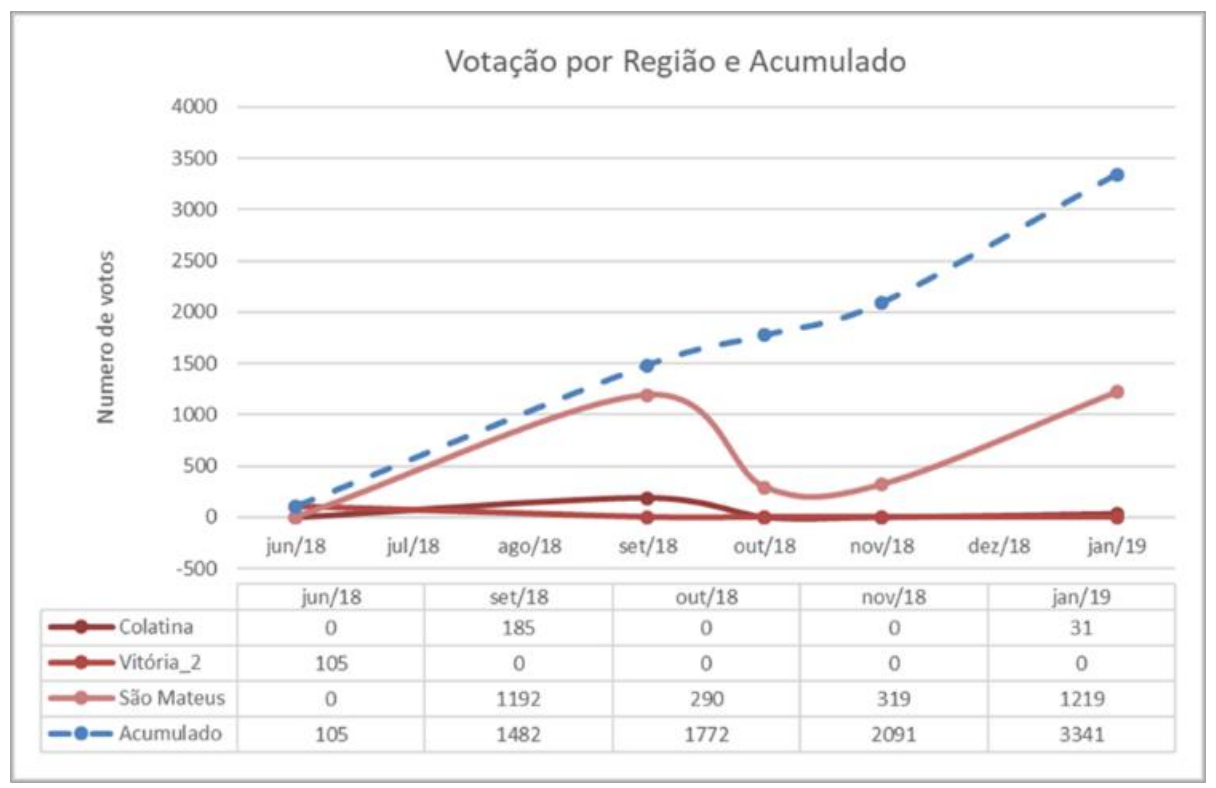

Fonte: Os autores (2019)

Figura 6 - Espírito Santo: evolução de votações

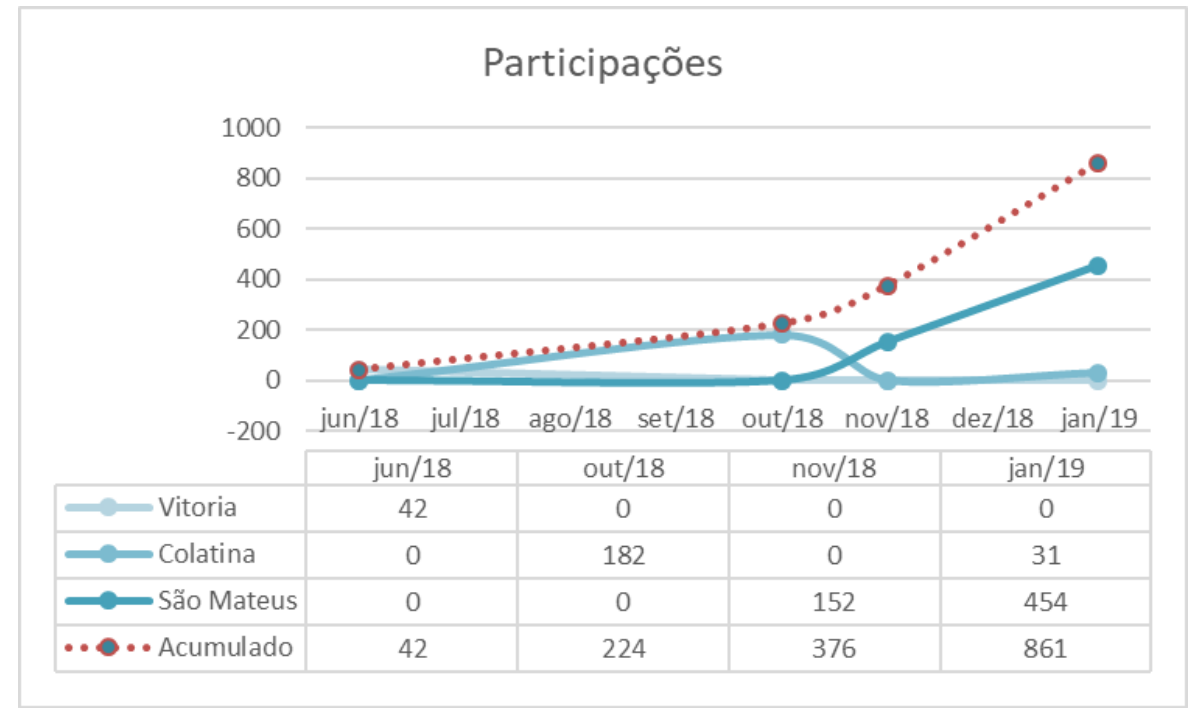

Fonte: Os autores (2019) 
Figura 7 - Espírito Santo: evolução de participantes

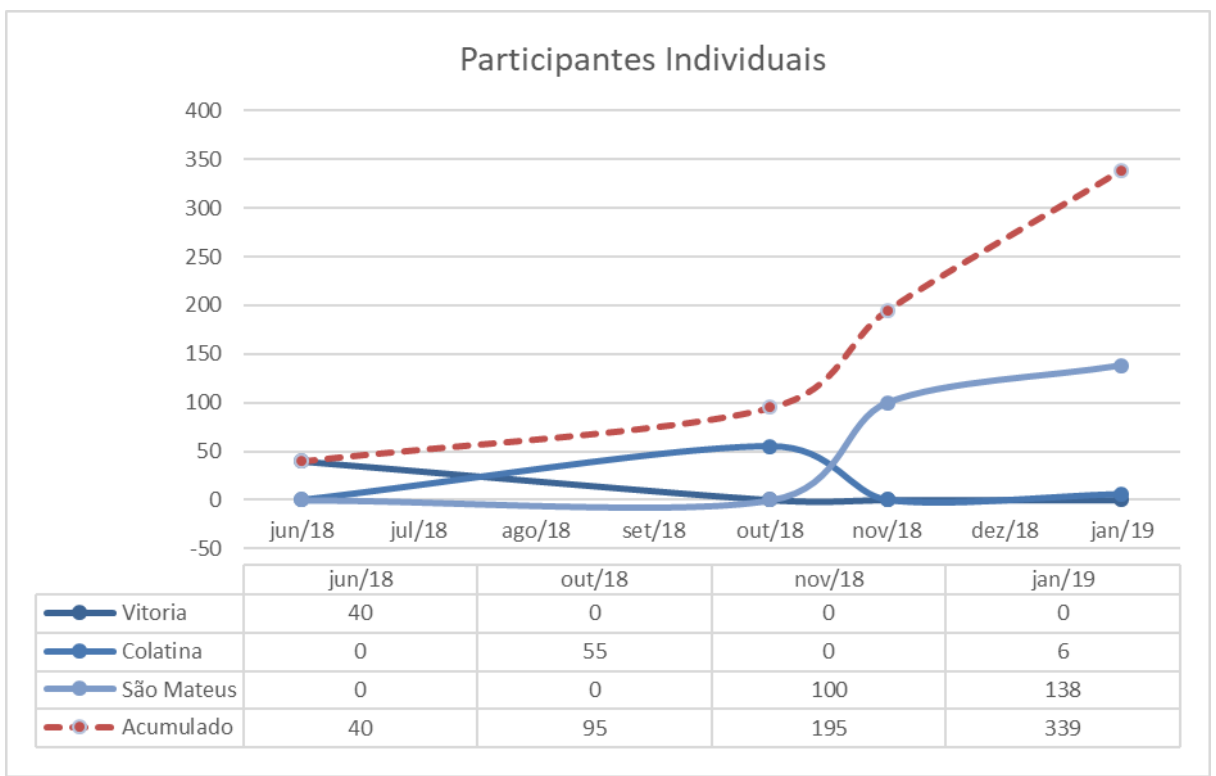

Fonte: Os autores (2019)

Ao observarmos a evolução do cômputo geral das votações acumuladas (Figura 8), podemos observar que no período de consulta o tema meio ambiente perdeu importância relativa frente ao tema saúde, que passa a ganhar relevância e se aproxima do tema trabalho.

Figura 8 - Espírito Santo: evolução de votações por tema (acumulado)

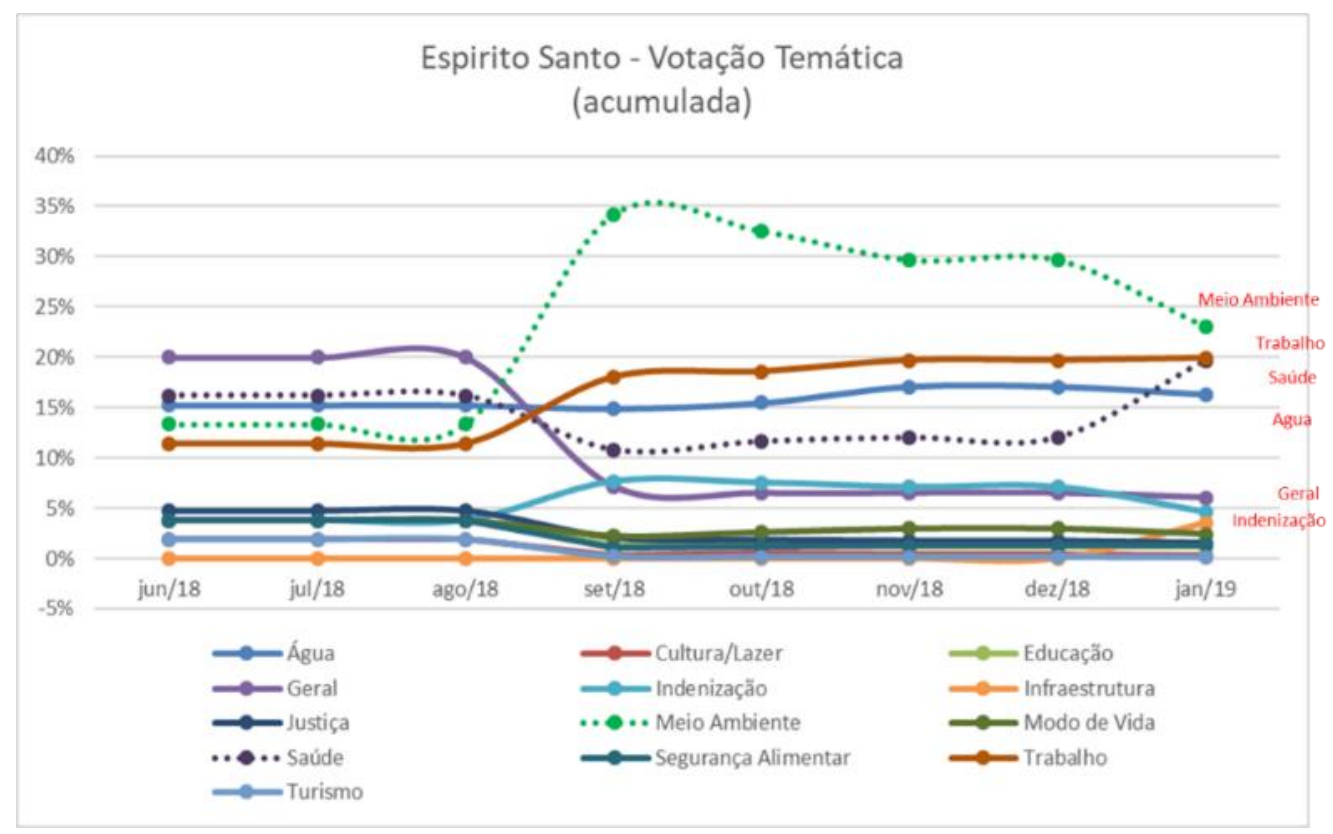

Fonte: Os autores (2019)

Ainda que a votação expressiva de São Mateus tenha influenciado o cômputo geral (Espírito Santo), o modelo de dados preservou a expressão e processo de formulação de agenda das demais comunidades, ou unidades territoriais, independentemente do seu tamanho. Ao conduzir painéis simultâneos e compartilhar dados localmente e por todo território foi possível observarmos comportamentos diferenciais de cada região e entre essas e o cômputo geral (Figura 9). 
Figura 9 - Mapa de temas mais votados por município e geral - \% (status Jan. 2019

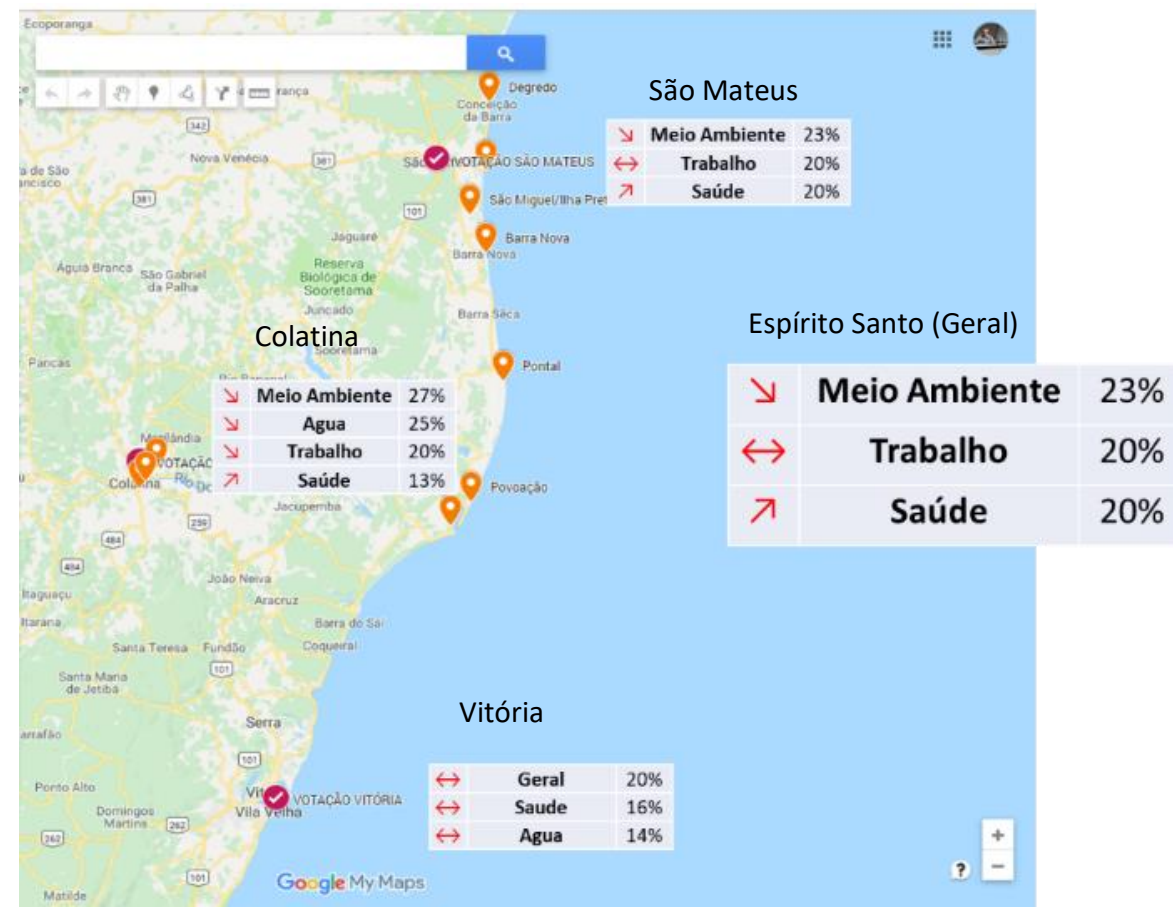

Fonte: Os autores (2019)

Sendo assim, é possível constatar que apesar dos resultados em Espírito Santo reproduzirem os resultados em São Mateus - Meio Ambiente 23\% \, Trabalho 20\% ↔, e Saúde 20\% $\lambda$, em Colatina a incidência de votações ocorreu de modo diferente dentro dos temas em debate - Meio Ambiente 27\% ע , Agua 25\% ע, Trabalho 20\% ע e Saúde 13\% $\pi$. O procedimento utilizado tornou possível observar, portanto, que a incidência de cada tema no cômputo geral de votações varia de lugar de lugar, ou seja, observar e comparar preferências em comunidades de diferentes escalas sem prejuízo da dinâmica participativa de cada uma delas.

Figura 10 - Mapa de Isolinha: tema Saúde (status Jan. 2019

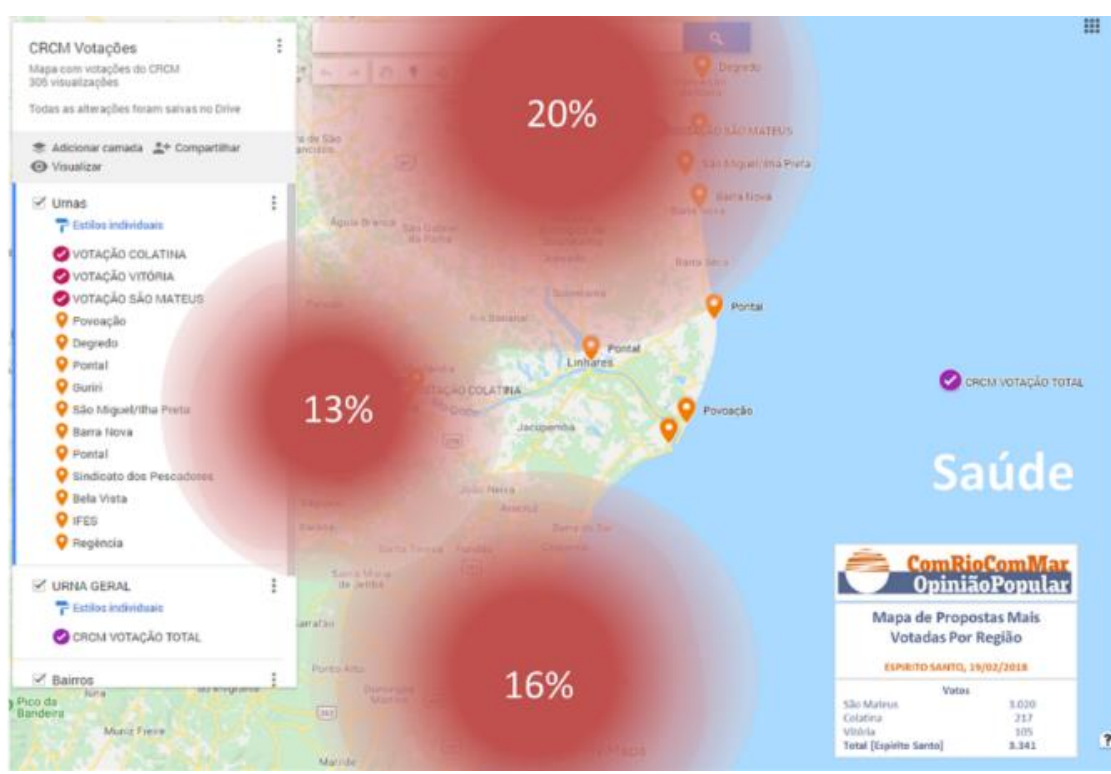

Fonte: Os autores (2019) 
Esse mesmo resultado é acima representado de maneira topológica, onde a incidência diferencial de votos em um tema pode ser observada como um todo (Figura 10).

Por outro lado, ao examinarmos as listas de proposições e votações, algo passível de ser feito tanto tematicamente quanto territorialmente, torna-se possível observar aspectos narrativos dessas dimensões temáticas e territoriais.

Abaixo relacionamos as 20 propostas mais votadas no período setembro-dezembro no cômputo geral de votações (Espírito Santo). Nessa lista encontramos proposições e manifestações de diferentes temas (Tabela 1).

Tabela 1 - Espírito Santo: Setembro a Dezembro - 20 proposições mais votadas

\begin{tabular}{|c|c|c|}
\hline Código & Proposição & Votos \\
\hline 110.080 & $\begin{array}{l}\text { Queremos estudos nas águas e peixes nos segmentos até mesmo nas } \\
\text { populações ribeirinhas }\end{array}$ & 173 \\
\hline 110.046 & Trabalho e programas que geram renda para os impactados pela lama & 171 \\
\hline 110.032 & $\begin{array}{l}\text { A lama atingiu o nosso pesqueiro, o que afeta o meu rendimento } \\
\text { econômico e da minha família }\end{array}$ & 160 \\
\hline 110.013 & Saúde & 155 \\
\hline 110.065 & Análise do lençol freático & 145 \\
\hline 110.044 & Melhores condições de saúde & 123 \\
\hline 110.066 & Análise do peixe do rio Cricaré & 121 \\
\hline 110.096 & Ponte para ir à São Mateus, entre Barra Nova Sul e Barra Nova Norte & 116 \\
\hline 110.024 & Tomar uma atitude honesta pagando o povo atingido & 103 \\
\hline 110.038 & Água & 101 \\
\hline 110.027 & $\begin{array}{l}\text { Que as pesquisas possam organizar nossas comunidades e possam criar } \\
\text { projetos para água, saúde, trabalho e mudanças nos modos de vida }\end{array}$ & 99 \\
\hline 110.036 & Quero nosso pesqueiro de volta para ser mais feliz & 77 \\
\hline 110.108 & Posto de saúde & 73 \\
\hline 110.071 & Análise dos camarões, mariscos e peixes de nossas regiões & 71 \\
\hline 110.083 & Água de qualidade para beber & 69 \\
\hline 110.063 & Análise do camarão da Foz Norte e Sul do Rio Doce & 68 \\
\hline 110.092 & Posto de Saúde com médicos e atendente educados & 55 \\
\hline 110.031 & Água de melhor qualidade & 54 \\
\hline 110.060 & $\begin{array}{l}\text { Queremos uma solução sobre como vamos viver sem o nosso trabalho se } \\
\text { somos pescadores }\end{array}$ & 53 \\
\hline
\end{tabular}

Fonte: Os autores

A manipulação textual dessas proposições, feita ou não em conjunto com os próprios atingidos, permite uma acepção narrativa da interação coletiva dos envolvidos nesse processo. Considerando a atribuição de votos (peso) a cada proposição, torna-se possível ainda a aferição quantitativa do peso proporcional dessa narrativa dentro do conjunto global de proposições (força narrativa).

Recortes territoriais e/ou temáticos específicos são ainda passíveis do mesmo tipo de análise.

Ao voltar nossos olhos as propostas mais votadas, contanto, podemos observar diferenças entre prioridade gerais e locais (Figura 11). São Mateus apresentou como prioridade "trabalho e programas de geração de renda" (5,65\% dos votos), Colatina "continuar trabalhando na mesma profissão" (6,42\%), Vitória simplesmente "Saúde" $(3,81 \%)$ e o cômputo geral (Espirito Santo) "estudos (de contaminação) nas águas, nos peixes e nas 
populações ribeirinhas" (5,17\%). Esses dados revelam que a preocupação por estudos sobre contaminação ambiental não é prioritária em nenhuma das áreas examinadas mas figura como a principal preocupação considerando todas localidades.

Figura 11 - Proposta mais votada por município e geral - \% (status Jan. 2019)

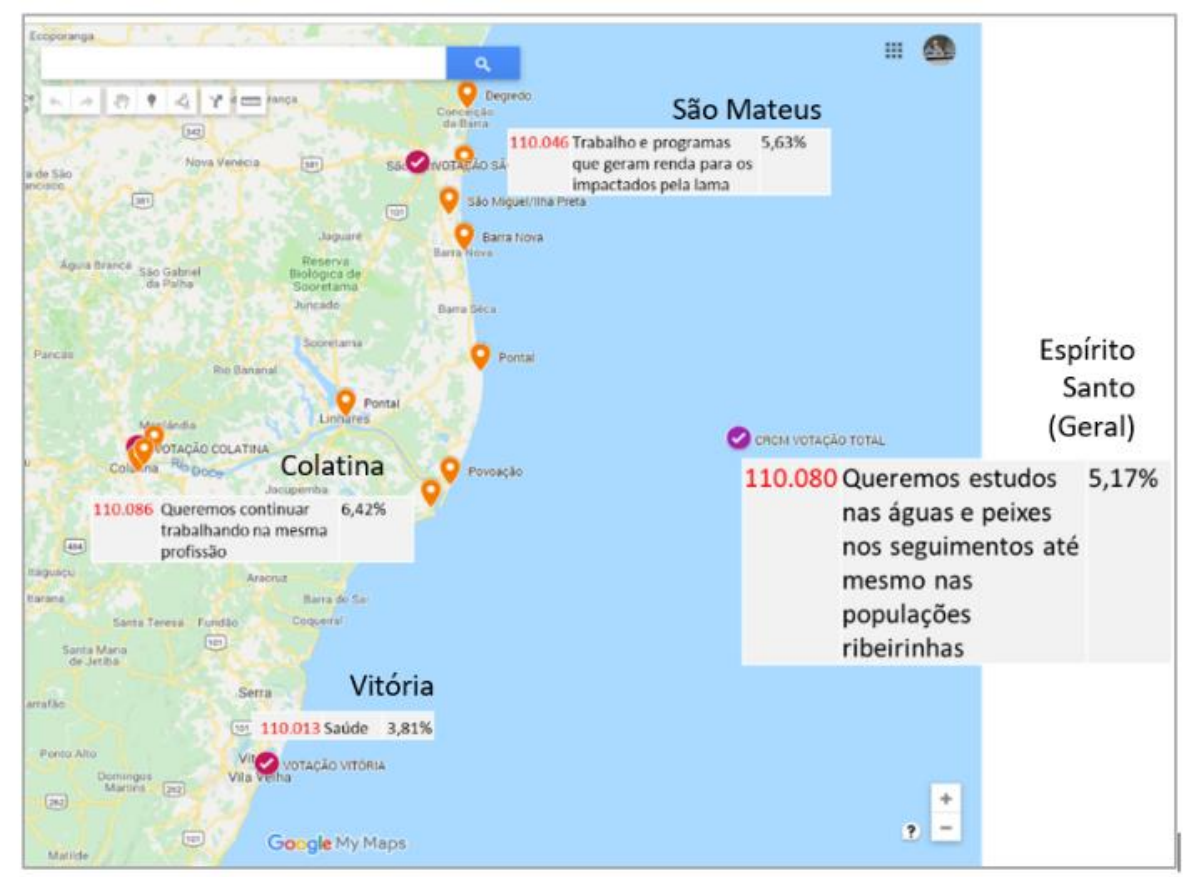

Fonte: Os autores (2019)

Se por um lado, São Mateus aponta para a possibilidade de formulação de uma visão de futuro, Colatina manifesta um desejo de continuidade de atividade profissional (pesca), algo impossível considerando a contaminação ambiental daquele bioma, i.e., denotando uma postura de negação no que toca sua atual situação ambiental. Vitória, por sua vez, ao elencar simplesmente Saúde como prioridade local, não especifica se faltam postos ou unidades de Saúde, onde faltam, ou se há dificuldade de acessar serviços ou especialidades específicas.

Observamos, portanto, no que toca a aplicação dessa pesquisa, diferentes graus de maturidade na condução de debates em cada região.

\section{CONCLUSÕES}

O presente trabalho descreve sucintamente os processos e o modelo de dados empregados na implementação de uma plataforma de governança participativa no litoral do Espírito Santo. Para tal, procurou-se desenvolver e testar uma ferramenta analítica interdisciplinar cujo objetivo é fomentar a reflexão coletiva e a construção de consensos, respeitando a expressão de interesses e significados implicados nas relações entre atores locais.

Resultados apontam que o emprego de ciclos contínuos de estímulo (votação) e resposta (resultado) em âmbito coletivo criam dinâmicas sociais sistêmico-responsivas de ação coletiva sensíveis ao contexto ambiental, manifesto no próprio elenco de prioridades coletivas, objeto do processo. Tal efeito foi observado em âmbito multiescalar e multitemático nas experiências realizadas.

Contudo, aspectos operacionais e conceituais compreendendo o controle de coleta de dados, randomização de amostragens e validação interna e externa do experimento devem ainda ser explorados amiúde para validação científica desse experimento. 
Superados esses desafios, vislumbra-se a possibilidade de aplicar essa componente no desenho e implementação de políticas públicas e assim incrementar a acuidade da alocação de bens e serviços contribuindo para o aperfeiçoamento de práticas socialmente sustentáveis de desenvolvimento.

\section{AGRADECIMENTOS}

Esta pesquisa foi desenvolvida no âmbito do Projeto no 88881.118026/2016-01 CAPESFAPEMIG-FAPES-CNPq-ANA.

Mais detalhes podem ser obtidos no endereço www.comriocommar.com.br

\section{REFERÊNCIAS}

CENTOLA, Damon et al. Experimental evidence for tipping points in social convention. Science, v. 360, n. 6393, p. 1116-1119, 2018.

GURZA LAVALLE, Adrián; ISUNZA VERA, Ernesto. Precisiones conceptuales para el debate contemporáneo sobre la innovación democrática. La innovación democrática en América Latina: tramas y nudos de la representación, la participación y el control social, p. 17-82, 2010.

HONG, LU; PAGE, Scott E. Some microfoundations of collective wisdom. Collective Wisdom, p. 56-71, 2008.

IWANAGA, Saori; NAMATAME, Akira. The complexity of collective decision. Nonlinear Dynamics, Psychology, and Life Sciences, v. 6, n. 2, p. 137-158, 2002.

Efficiency and equity in collective systems of interacting heterogeneous agents. In: Collectives and the Design of Complex Systems. Springer New York, 2004. p. 257-276.

Influence of Partner Selection on Functional Differentiation: Emergence of Diversity by Isolated Interaction and Preference Change. JOURNAL OF ROBOTICS NETWORKING AND ARTIFICIAL LIFE, v. 3, n. 4, p. 257-264, 2017.

ISUNZA, E., \& GURZA, A. (Eds.). (2018). Controles democráticos no electorales y regímenes de rendición de cuentas en el Sur Global. Bern, Switzerland: Peter Lang UK. Retrieved Jun 21, 2019, from https://www.peterlang.com/view/title/63743

LANDEMORE, Hélène; ELSTER, Jon (Ed.). Collective wisdom: Principles and mechanisms. Cambridge University Press, 2012.

LANDEMORE, Hélène. The Mechanisms of Collective Intelligence in Politics. Collective Wisdom. Principles and Mechanisms, Cambridge, CUP, p. 251-289, 2012.

Why the many are smarter than the few and why it matters. Journal of public deliberation, v. 8, n. 1, p. 7, 2012.

Deliberative democracy as open, not (just) representative democracy. Daedalus, $v$. 146, n. 3, p. 51-63, 2017.

LAVALLE, Adrián Gurza; HOUTZAGER, Peter P.; CASTELLO, Graziela. Democracia, pluralização da representação e sociedade civil. Lua Nova, n. 67, 2006

LAVALLE, Adrian Gurza et al. Movimentos sociais, institucionalização e domínios de agência. Centro de Estudos da Metrópole (CEM), Série Textos para Discussão CEM, n. 19, p. 3-40, 2017. 
LEIRNER, Andre. (2012). Painel de Opinião Popular - POP: gestão social responsiva e expressão popular na periferia de são Paulo. Anais XII ENAPEGS, PUC, SP.

(2009). Elementos Para a Construção de um Modelo de Voz Pública. Anais XIV Congreso del CLAD, CLAD, Salvador, Bahia

MARCHEZINI, Victor. As ciências sociais nos desastres: um campo pesquisa em construção. BIB, No.83 1/2017

ONG, Cheng Boon. Tipping points in Dutch big city neighbourhoods. Urban studies, v. 54, n. 4, p. 1016-1037, 2017. 